\title{
EDITORIAL
}

\section{Medical and Sporting Ethics of High Altitude Mountaineering: The Use of Drugs and Supplemental Oxygen}

Historically, mountaineers have carried the glucocorticoid dexamethasone in their first aid kits as a last resort emergency drug for the treatment of potentially fatal high altitude cerebral edema (HACE). In the past few years, it seems that this drug is gaining acceptance as a prophylaxis for acute mountain sickness rather than be limited to an emergency treatment for HACE. A recent case report described a climber on Mount Everest taking a daily cocktail of acetazolamide, dexamethasone, and nifedipine as advised by his physician for the purpose of preventing acute mountain sickness, HACE, and high altitude pulmonary edema (HAPE). ${ }^{1}$ The climber eventually had steroid toxicity and had to undergo extensive treatment.

At the 8th World Congress on High Altitude Medicine and Physiology in Arequipa, Peru, in 2010, there was a spirited debate over the increased use of drugs for the purpose of climbing high mountains. Are physicians who prescribe medication to facilitate acclimatization or improve climbing performance guilty of dispensing performance-enhancing drugs, or are they upholding their medical oath by protecting the health of climbers who may be at risk for HACE or HAPE? Some of the world's most respected authorities on mountain medicine had opposing viewpoints, with both sides making valid arguments. Since that time, several studies have been published that further fuel this debate and cause one to question the medical and sporting ethics of high altitude mountaineering.

Mountaineers have always had to make personal decisions regarding the use of climbing aids (eg, fixed ropes, supplemental oxygen, and so forth) and what constitutes climbing a mountain in "good style" versus cheating. Like it or not, physicians are now dragged into this ethical dilemma because the drugs being used by some mountaineers require a prescription. According to the World Anti-Doping Code, ${ }^{2}$ a substance is considered for inclusion on the prohibited list if it meets 2 of 3 criteria: 1) enhances sport performance; 2) poses a potential health risk to the athlete; and 3) violates the spirit of sport. Additionally, the International Federation of
Sports Medicine states that encouraging or assisting athletes to use banned substances is unethical and forbidden. ${ }^{3}$ It should be noted that both acetazolamide and dexamethasone are included on the prohibited substance list by the World Anti-Doping Agency, ${ }^{4}$ yet these drugs are also recommended for the prevention and treatment of altitude illness by the Wilderness Medical Society (WMS). ${ }^{5}$

On the one hand, the position that using these drugs to aid in climbing a mountain is unethical seems valid. Acetazolamide has been shown to enhance exercise and cerebral oxygenation at altitude. ${ }^{6,7}$ Dexamethasone improves cognitive performance ${ }^{8,9}$ and exercise capacity ${ }^{10,11}$ at altitude. That is strong evidence that these are performance-enhancing drugs. Is writing a prescription for acetazolamide or dexamethasone for a climber so that he or she can perform better on a mountain any different from prescribing an anabolic steroid to a ball player to hit a ball further or administering erythropoietin to a cyclist to ride faster? On the other hand, one of the main tenets of the anti-doping $\operatorname{code}^{2}$ is the protection of the athlete's health. It is well known that these drugs reduce the incidence of altitude illness. Also, if they help a climber think more clearly and move faster above $8000 \mathrm{~m}$, that could be lifesaving. Thus, it seems irresponsible for a physician to not promote the use of these drugs.

Taking this debate one step further, the use of supplemental oxygen also appears to meet the criteria for a prohibited substance as supplemental oxygen clearly enhances performance at high altitude, and many elite climbers are of the opinion that its use violates the spirit of sport. ${ }^{12}$ Indeed, some have called for the World AntiDoping Agency to include supplemental oxygen on the banned list and for the International Mountaineering and Climbing Federation to not acknowledge ascents made with supplemental oxygen. ${ }^{12}$ In short, they are of the opinion that using supplemental oxygen or drugs is cheating. It is unlikely that such a ban would ever be enforced, but imagine the consequences. There would be a substantial reduction in the number of climbers attempting high mountains, but the death rate would also 
likely increase. Death rates on the world's highest mountains are significantly increased by about threefold for attempts made without supplemental oxygen. ${ }^{13}$

I have not provided any solution for this debate about whether drugs and supplemental oxygen have a place in high altitude mountaineering and about what role physicians should play. The purpose of this brief commentary was simply to stimulate dialog and present both sides of the issue. There will not be any drug testing at the base camps of $8000 \mathrm{~m}$ peaks. Climbers will continue to search their own personal conscience for what it means to climb by fair means. As physicians get more requests to fill prescriptions for medications that are both therapeutic and performance-enhancing drugs, they will have to search their consciences as well. It seems prudent that the International Mountaineering and Climbing Federation and major sports medicine and mountain medicine organizations (eg, World Anti-Doping Agency, International Federation of Sports Medicine, WMS, and International Society of Mountain Medicine) work together to arrive at some consensus on this issue.

Dale R. Wagner, $\mathrm{PhD}$ Human Movement Science Program Health, Physical Education, and Recreation Department, Utah State University Logan, UT

\section{References}

1. Subedi BH, Pokharel J, Goodman TL, et al. Complications of steroid use on Mt. Everest. Wilderness Environ Med. 2010;21:345-348.

2. World Anti-Doping Agency (WADA). World anti-doping code. Available at: http://www.wada-ama.org/en/world-antidoping-program/sports-and-anti-doping-organizations/thecode/. Accessed March 16, 2012.

3. International Federation of Sports Medicine (FIMS). Position statement on doping in sport. Available at: http:// www.fims.org/en/position-statements/previously-published/. Accessed March 16, 2012.

4. World Anti-Doping Agency (WADA). The 2012 prohibited list: international standard. Available at: http://www.wadaama.org/en/world-anti-doping-program/sports-and-antidoping-organizations/international-standards/prohibited-list/. Accessed March 16, 2012.

5. Luks AM, McIntosh SE, Grissom CK, et al. Wilderness Medical Society consensus guidelines for the prevention and treatment of acute altitude illness. Wilderness Environ Med. 2010;21:146-155.

6. Lafleur JE, Bartniczuk D, Collier A, Griffin N, Swenson ER. Acetazolamide and exercise hypoxia. Int J Sports Med. 2010;31:372-376.

7. Vuyk J, Van Den Bos J, Terhell K, et al. Acetazolamide improves cerebral oxygenation during exercise at high altitude. High Alt Med Biol. 2006;7:290-301.

8. Jobe JB, Shukitt-Hale B, Banderet LE, Rock PB. Effects of dexamethasone and high terrestrial altitude on cognitive performance and affect. Aviat Space Environ Med. 1991; 62:727-732.

9. Lafleur J, Giron M, Demarco M, Kennedy R, BeLue R, Shields C. Cognitive effects of dexamethasone at high altitude. Wilderness Environ Med. 2003;14:20-23.

10. Fischler M, Maggiorini M, Dorschner L, et al. Dexamethasone but not tadalafil improves exercise capacity in adults prone to high altitude pulmonary edema. Am J Respir Crit Care Med. 2009;180:346-352.

11. Siebenmann C, Bloch KE, Lundby C, Nussbamer-Ochsner Y, Schoeb M, Maggiorini M. Dexamethasone improves maximal exercise capacity of individuals susceptible to high altitude pulmonary edema at 4559 m. High Alt Med Biol. 2011;12:169-177.

12. Twight MF. Powered by skill or doped with $\mathrm{O}_{2}$ ? E9Climbing. 14 September 2010. Available at: http:// e9climbing.blogspot.com/2010/09/powered-by-skill-ordoped-with-o2.html. Accessed March 16, 2012.

13. Huey RB, Eguskitza X. Supplemental oxygen and mountaineer death rates on Everest and K2. JAMA. 2000;284: 181. 